\title{
$\mathrm{CSCF}$ 노드 관리를 이용한 응용 서비스 구현추
}

\section{The Implementation of Application Services Using CSCFs of Management}

\author{
이 재 오* \\ 조 재 형** \\ Jae-Oh Lee \\ Jae-Hyoung Cho
}

요 약

최근 네트워크간의 통합으로 인하여 네트워크 통합 관리 시스템 중 하나인 IMS (IP Multimedia Subsystem)의 사용이 증가하고, 이로 인해 네트워크 트래픽이 증가하고 있다. 따라서 IMS에서의 자원을 효율적으로 관리하기 위하여 네크워크 관리 시스템의 기능이 점차 커지고 있다. 특히 IMS 노드에 트래픽은 유동적이기 때문에 이것을 효과적으로 관리하기 위해서는 적절한 동적 라우팅 구조가 필요 하다. 따라서 본 논문에서는 IMS 노드간의 트래픽을 제어하기위한 동적 알고리즘 구조를 제안하고, IMS의 대표적인 응용서비스인 Presence Service와 PoC (Push to talk over Cellular)를 이용하여 본 알고리즘의 성능을 측정한다.

\section{ABSTRACT}

Recently, according to increasing the network traffic in the IMS, the role of Network Management System (NMS) is very important because of limited network resource. NMS can perform two kinds of routing ways with the capability of static or dynamic routing. The way of $A$ dynamic routing is more efficient than static routing one because it can make the flow of traffic changeful among nodes in the IMS. Therefore, in this paper, we suggest a management function of NMS, using a dynamic routing algorithm for managing the CSCFs in the IMS. And then we analyze the algorithm by measuring the performance of PoC, one of the prominent application services to be deployed in the IMS.

푸 keyword: IMS, NMS(네트워크 관리 서비스), 동적라우팅

\section{1. 서 론}

IMS는 All-IP 환경에서 SIP(Session Initiation Protocol) 을 기반으로 하여 음성, 오디오, 비디오, 데이터등의 멀티 미디어 서비스를 복합 제공하는 시스템이다. 인터넷에서 통합을 쉽게 하기 위해, IMS는 IETF 권고하는 SIP를 사용 하여 어디서나 서비스를 제공할 수 있으며 또한 네트워크 관리 시스템을 이용하여 QoS (Quality of Service)를 보장 할 수 있다[1]. 이러한 $\mathrm{QoS}$ 를 보장하기 위해서는 IMS 노 드의 자원을 적절하게 관리할 수 있는 네트워크 관리 시 스템이 필요하다.

$\mathrm{IMS}$ 는 다수의 CSCF (Call Session Control Function) 로 구성되며 $\mathrm{CSCF}$ 들의 성능을 평가하여 적절한 노드를 선 * 정 회 원 : 한국기술교육대학교 전기전자통신공학부 교수
jolee@kut.ac.kr (교신저자)

** 정 회 원 : 한국기술교육대학교 대학원 전기전자공학과 수료(박사) tlsdl2@kut.ac.kr

[2011/11/24 투고 - 2011/12/14 심사(2012/01/31 2차) - 2012/04/02 심사완료]

누 본 논문은 한국기술교육대학교 교육연구 진흥비 지원에 의 하여 연구되었음
택한 후 라우팅 과정을 수행하기 위한 관리기능이 필요하 다. 또한 이러한 $\mathrm{CSCF}$ 의 상태는 성능, 고장, 트래픽에 따 라 달라질수 있으므로 이를 포함할 수 있는 라우팅 알고 리즘이 필요할 것이다. 또한 $\mathrm{CSCF}$ 의 트래픽은 유동적이 기 때문에 트래픽의 변화에 따라 유연하게 대처할 수 있 는 동적 라우팅 알고리즘을 적용해야 할 것이다.

따라서 본 논문은 IMS 세션처리를 담당하는 $\mathrm{CSCF}$ 간 의 성능 관리를 위한 동적 라우팅 알고리즘 구조를 제안하 고, 이를 이용하여 $\mathrm{IMS}$ 의 대표적인 서비스인 Presence Service와 PoC 서비스를 이용하여 해당 알고리즘의 성능을 측정한다. 2장에서는 SNMP (Simple Network Management Protocol) 및 IMS구조를 살펴본 후 3장에서는 구현한 Presece Service와 PoC 서비스와 제안된 동적 라우팅 알고 리즘을 살펴본다. 그리고 4장에서는 이를 토대로 성능을 평가하며, 마지막으로 5장에서 결론을 도출한다.

\section{2. 관련연구}

\subsection{IMS 구조}

$\mathrm{IMS}$ 의 주된 목적은 IP기반으로 음성, 비디오, 멀티미 


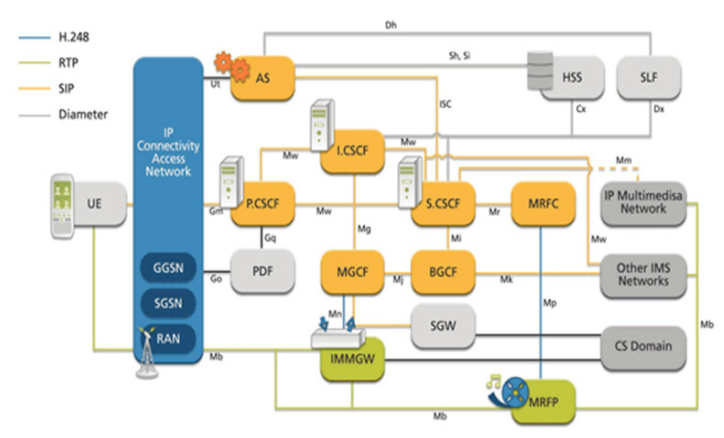

(그림 1) IMS의 구조

디어 서비스를 제공하는 것이다. 또한 IMS는 개발에 용이 하며, 수정하기 쉽다는 장점을 가지고 있다. 따라서 이는 응용 프로그램을 개발하는 개발자들에게 다양한 네트워 크를 고려하지 않아도 개발할 수 있는 환경을 제공한다. 또한 IMS는 IETF 표준 프로토콜 중 하나인 SIP를 이용하 여 $\mathrm{CSCF}$ 들을 관리하며, 이러한 $\mathrm{CSCF}$ 관리 기능에는 $\mathrm{QoS}$, 과금, 보안등이 포함된다. (그림 1)은 IMS의 구조를 표현 한 것이다[2].

관리 시스템과 IMS는 SNMP를 이용하여 정보를 주고받 는다. 그리고 IMS는 다수의 $\mathrm{CSCF}$ 와 HSS(Home Subscriber Server)로 구성되어있다. P(Proxy)-CSCF는 단말이 Access 네트워크를 통하여 IMS망에 접속하는 지점이다. P-CSCF 의 역할은 프록시와 사용자 에이전트(UA)의 역할을 수행 하면서 사용자로부터 수신한 SIP REGISTER 메시지를 사 용자의 홈 도메인을 참조하여 I(Interrogating)-CSCF로 전 달한다. 그리고 사용자로부터 수신한 SIP 메시지를 등록 절차에 따라 $\mathrm{S}$ (Serving)-CSCF로 전달하고, 사용자에게 SIP 메시지를 요구 또는 응답한다[3]. 또한 $\mathrm{PDF}$ (Policy Decision Function)를 이용하여 QoS를 보장할 수 있다.

I-CSCF는 사용자의 홈 네트워크 도메인에 속하는 첫번 째 지점으로써, 하나의 네트워크 도메인에 여러 개 존재 할 수 있다. 다른 네트워크로부터 수신한 SIP메시지를 $\mathrm{S}-\mathrm{CSCF}$ 로 라우팅하고 HSS로부터 S-CSCF의 주소를 획득 한다. S-CSCF는 주로 사용자의 인증 및 정보를 $\mathrm{HSS}$ 에 등 록하고 이후 사용자의 가입자 정보를 다운로드하여 유지 한다. 그리고 해당 서비스를 제공하기 위한 서비스 플랫 폼과의 상호작용과 함께 사용자에게 서비스 자원과 관련 된 정보를 제공한다. $\mathrm{HSS}$ 는 $\mathrm{CS} / \mathrm{PS}$ 도메인 그리고 $\mathrm{IMS}$ 를 통한 가입자의 이동성 관리, 호와 세션 설정지원, 가입자 의 보안 정보 생성, 가입자 인증, 메시지의 무결성 체크와 암호화를 위한 데이터 생성, 생성된 데이터 저장, 서비스

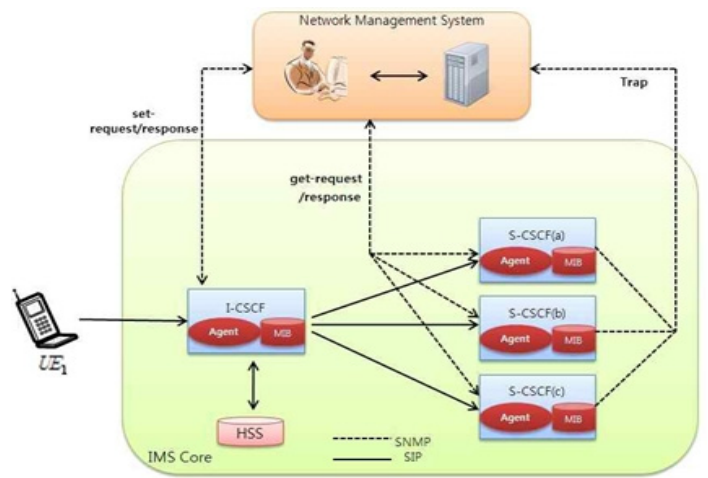

(그림 2) 동적라우팅을 이용한 네트워크 관리시스템

별 가입자식별자 관리 처리 등을 담당한다. 또한 CSCF와 $\mathrm{NMS}$ 와의 인터페이스는 대표적인 관리 프로토콜인 $\mathrm{SNMP}$ 를 이용하여 $\mathrm{CSCF}$ 노드들의 성능정보를 수집한다.

$\mathrm{SNMP}$ 는 네트워크 관리시 이용되는 네트워크 관리 프 로토콜이다. $\mathrm{SNMP}$ 는 폴링방식을 이용하며, $\mathrm{CSCF}$ 는 노드 의 상태 및 성능 정보가 포함되어 있는 $\mathrm{MIB}$ 값을 주기적 관리 시스템에게 전송한다. 이러한 $\mathrm{MIB}$ 값을 토대로 관리 시스템은 네트워크 장비 또는 IMS의 노드들을 관리할 수 있다. SNMP는 관리 시스템과 관리 에이전트 간에 Get-Request, Get-Next-Request, Get-Response, Set-Request, $\mathrm{Trap}$ 의 명령어를 이용해 $\mathrm{MIB}$ 에서 정보를 교환한다[4]. 본 논문에서는 $\mathrm{SNMP}$ 를 이용하여 $\mathrm{CSCF}$ 관리시스템 알고리 즘을 제안하고 구현할 것이며 많은 노드들의 성능정보는 다양한 요인(고장, 트래픽증가등)의 이유로 바뀔 수 있으 므로, 이에 따라 $\mathrm{CSCF}$ 는 노드간의 적절한 라우팅 경로를 변경해야 한다. 따라서 본 연구에서는 네트워크 상황에 따라 효과적으로 대응하기 위한 동적 라우팅 알고리즘을 토대로 제안할 것이다.

동적 라우팅은 $\mathrm{MIB}$ 에서 추출한 값을 분석하여 성능이 좋은 $\mathrm{CSCF}$ 로 라우팅 경로를 변경한다. (그림 2)는 동적라 우팅 알고리즘을 이용한 네트워크 관리시스템의 구조를 표현한 것이다.

관리 시스템에 다수의 $\operatorname{S-CSCF}(a, b, c)$ 가 존재할 경우 라우팅 할 S-CSCF의 주소를 I-CSCF에게 전달하고 절절 한 S-CSCF를 선택하여 SIP 메시지를 전달하는 과정을 보 여준다. 성능을 표현 하는 정보는 다양하지만, 본논문에 서는 시스템의 주요 성능 요소인 시스템의 동작상태, $\mathrm{CPU}$ 및 메모리의 임계값을 이용하여 알고리즘을 작성하 였다. 이를 이용하여 SIP 메시지는 가장 성능이 좋은 $\mathrm{S}-\mathrm{CSCF}$ 를 선택할 수 있다. 


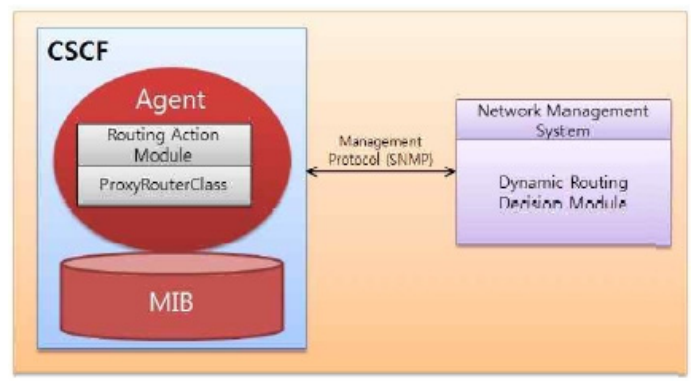

(그림 3) 동적라우팅을 위한 에이전트의 구조

(그림 3)은 동적 라우팅을 지원하기 위한 에이전트의 구조이다. $\mathrm{CSCF}$ 에 있는 관리 에이전트는 주기적으로 성 능 관련 정보 $(\mathrm{MIB})$ 를 관리 시스템에 제공한다. 관리 시 스템은 이를 바탕으로 제안된 동적 알고리즘을 이용하여 관리 서비스를 수행한다. 다시 말하면, Dynamic Routing Decision Module에 따라 ProxyRouterClass 내부의 정보를 적용한다. 따라서 관리시스템은 $\mathrm{CSCF}$ 의 에이전트에게 SNMP를 이용하여 Routing Action Module을 제어함으로써 $\mathrm{SIP}$ 메시지의 동적라우팅을 수행할 수 있다.

\subsection{Presence Service}

Presence Service란 사용자의 사용여부 및 정보를 표현 하는 presence 정보를 수신하여 (PS) Presence Server에 등 록한 뒤 버디(buddy)로 등록된 사용자가 요청 하면, 해당 presence 정보를 전달하는 서비스이다[5]. PS는 사용자의 presence 정보를 관리하는 시스템이다. Presence Service에 는 인스턴트 메시징, $\mathrm{VoIP}$, 이메일 등의 통신 수단과 긴급 한 경우, 그리고 음성 메일 가능, 음성 또는 비디오 가능, 사용자의 이동성 같은 통신 능력이 포함되어 있다. $\mathrm{PS}$ 는 사용자의 presence 정보를 관리하는 시스템으로써 사용자 는 PS를 통해 자신의 presence 정보, 버디의 추가, 삭제 및 버디의 멀티미디어 presence 정보를 관리할 수 있다.

(그림 4)는 Presence Service의 간단한 구조이다. Presence Service는 presence 정보를 저장, 수락, 적절하게 정보를 분 배하는 역할을 하고, 사용자는 PUA (Presence User Agent) 를 통하여 자신의 presence 정보를 제공 한다. Watcher는 서비스로부터 presence 정보를 확인하고, 자신이 과거에 가지고 있던 presence 정보에서 변화된 값이 있다면 해당 되는 정보를 바꿔주는 역할을 수행한다. presence 서비스 에서 사용하는 프로토콜은 주로 $\mathrm{SIP}$ 를 사용하며, 상황 (policy, $\mathrm{QoS}, \mathrm{AAA}$ 가 필요한 경우)에 따라 $\mathrm{HSS}$ 와 연동을

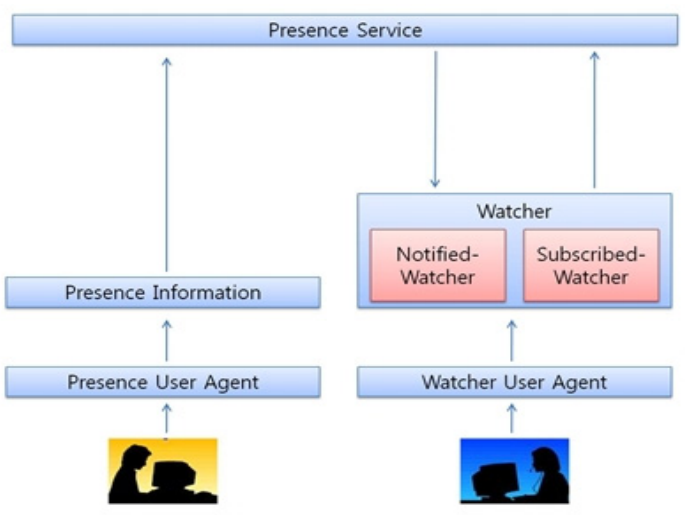

(그림 4) Presece Service의 구조

위해 Diameter를 사용한다.

presence 정보는 하나의 presence information은 적어도 한 개 이상의 튜플(tuple)로 구성되어있고, 각 튜플은 단말 이나 서비스의 상태를 표현하는 status(online, offline, busy, away) 통신을 위하여 사용된 수단(서비스 타입, 미디어 타 입)과 주소를 표현하는 Contact Address가 존재한다.

\subsection{PoC Service}

$\mathrm{PoC}$ 서비스는 휴대전화를 트랜시버처럼 사용하여, 버 튼을 누르고 있는 동안만 상대방과 통화 할 수 있도록 하 는 반이중식 통신서비스이다. 이는 음성을 데이터로 변환 하고, 패키지통신을 이용하여 상대방의 단말기에 보내는 VoIP 서비스의 일종이다[6].

상대방의 전화번호를 눌러 회선을 연결하는 것이 아니 라, 미리 등록해 놓은 상대방을 선택하여 버튼을 누리면 상대에게 음성 패킷을 송신하는 방식이며, 일반 통신처럼 양방향 통화는 불가능하며, 교대로 버튼을 눌러 발언권을 획득한 후 상대방과 통신하는 서비스이다. 전화와 달리 복수의 상대방을 그룹화 하여 그룹원들에게 동시에 음성 을 전달하는 기능도 제공한다.

$\mathrm{IMS}$ 에서 $\mathrm{PoC}$ 는 $\mathrm{SIP}$ 를 이용하여 메시지가 전달되며 해 당메시지에는 SIP 라우팅정보, 인증, $\mathrm{QoS}$ 를 위한 정보들 이 포함된다. (그림 5)는 OMA (Open Mobile Alliance)에서 권고하는 PoC Service의 구조 표준을 표현한 것이다.

PoC Service는 Session Negotiation을 하고 음성 데이터 를 송수신 하는 PoC Server, Presence정보를 제공하는 Presence Server, 그리고 통신 상태를 관리하는 $\mathrm{XML}$ Database Management Server(XDMS)로 구성되어있다. 


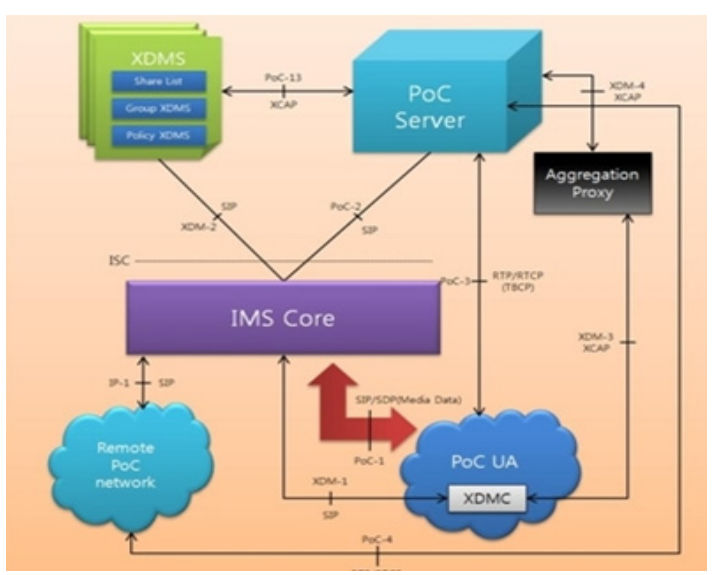

(그림 5) OMA표준에 의한 $\mathrm{PoC}$ 의 구조

위 $\mathrm{PoC}$ 구조도의 특징은 기능부(Functionality)와 데이 타부(XML Database)부의 두 가지로 분명하게 나뉘어 있 다는 점이다. $\mathrm{SIP} / \mathrm{IP}$ Core는 $3 \mathrm{GPP}$ 의 IMS, $3 \mathrm{GPP} 2$ 의 $\mathrm{MMD}$, 그 밖에 어떤 종류의 SIP Routing을 제공하는 네트워크를 의미한다. Aggregation Proxy는 Presence Server에서 필요한 buddy 정보와 PoC Server에서 필요한 buddy 정보 중의 한 쪽이 변경될 경우, 서로 다른 서버들에 분산되어 있는 동 일한 buddy 정보들의 변경을 통일시켜 주는 역할을 한다.

\section{3. 구 현}

\subsection{PoC 및 Presence Server}

(그림 6)은 구현한 Presence Server의 UML이다.

PresenceAgent는 Presence 서비스를 제공하는 SDP 내부 의 하나의 공통 서비스 구동자의 역할을 수행하고, SIP프 로토콜을 사용하며, PUBLISH, SUBSCRIBE, NOTIFY 메 시지를 처리하는 역할을 수행한다. PresenceServer의 역할 은 S-CSCF로 부터 SIP 메시지(PUBLISH, SUBSCRIBE, $\mathrm{NOTIFY)}$ 가 접근했을 때, 정보를 등록하고, ResourceList에 등록 정보를 업로딩 한다[7,8]. Pidfparser는 사용자와 엔 티티의 관련 정보(presence 및 presentity 정보, 접속지역, 단말의 상태등)에 관련된 정보를 XML형태로 만든다. 이 외의 다양한 정보를 태그(Tag) 형태로 정의하여 XML로 확장할 수 있다[9]. ResourceList는 사용자, 응용 서비스의 자원정보를 저장하도록 구현하였고, 추 후에 HSS와 연계 하여 사용자와 서비스의 인증, 과금, $\mathrm{QoS}$ 를 처리할 수 있

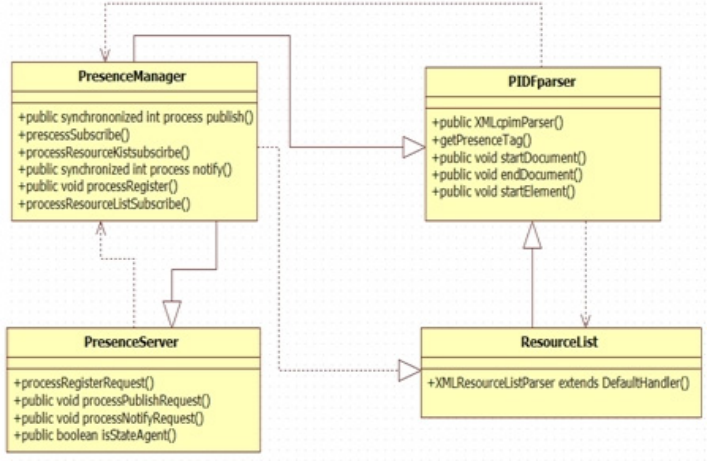

(그림 6) Presence Server UML

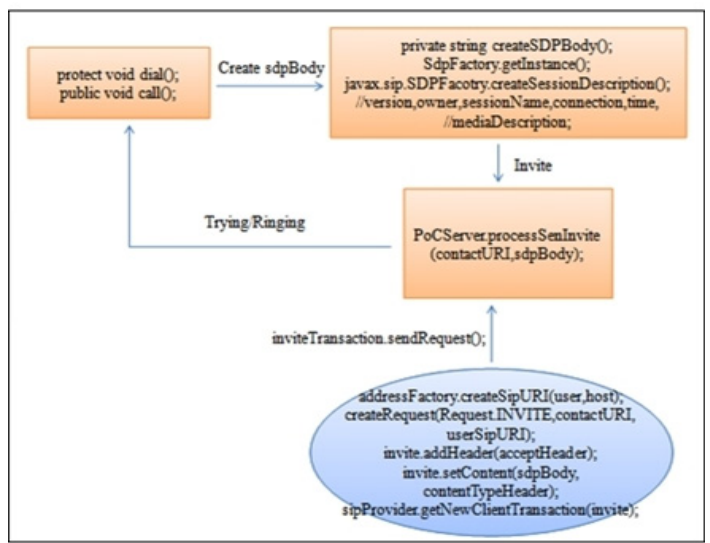

(그림 7) PoC를 이용한 INVITE 메시지 처리과정

도록 확장할 것이다. 먄약 SUBSCRIBE 메시지를 보낸 사 용자가 기존의 사용자라면, 기존의 presence 정보를 가져 오고, 상태 정보가 변동이 있다면 수정된 presence 정보만 을 수정하고, 신규 사용자라면 새로운 PIDF 문서를 만들 어 저장할 수 있도록 구현 되었다. Presence Manager는 PresnceServer가 제공하는 SIP 메시지와 ResourceList 정보 를 호출하여, 사용자 및 응용 서비스에게 적절한 SIP 메 시지를 만들어 처리한다.

(그림 7)은 $\mathrm{PoC}$ 를 이용한 메시지 처리과정을 보여준다. 'createRequest (Request.REGISTER, userSipURI, userSipURI)'를 이용하여 등록을 마친 후 'clientTransation.sendRequest();' 메소드를 만드는 작업이 필요하다. 하나의 Dialog는 사용 자간의 미디어 전송을위한 세션을 만들기 위하여 INVITE 메시지를 초기화한다. 사용자가 상대방과 통신하기 위한 call 버튼을 누르면 상대방 사용자에게 INVITE request메 


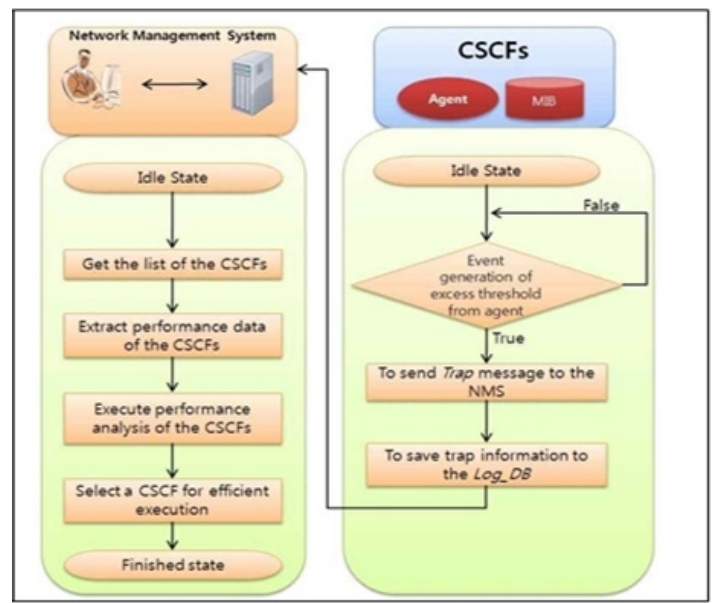

(그림 8) $\mathrm{CSCF}$ 동적 라우팅 알고리즘

시지를 전달하고 해당하는 응답을 기다린다.

$\mathrm{PoC}$ 세션 타입은 크게 두가지로 분류된다 : 1 대 1 방식 (one-to-one)과 1대다수(one-to-many) 1 대다수방식의 세션 은 ad-hoc, 채팅그룹과같은 정보를 추가적으로 포함한다. 휴대전화를 이용하여 $\mathrm{PoC}$ 서비스를 이용하여 통화하는 방 식이 1 대 1 방식이며, 본 구현에서는 1 대 1 방식만을 이용하 여 $\mathrm{PoC}$ 세션을 생성하였다.

\section{2 동적 라우팅 알고리즘을 이용한 관리 시스템}

(그림 8)은 앞에서 언급한 $\mathrm{MIB}$ 에 포함되는 $\mathrm{CSCF}$ 정보 를 이용하여 관리를 위한 동적라우팅 알고리즘을 표현한 것이다.

관리 시스템은 주기적으로 $\mathrm{CSCF}$ 에이전트로부터 성능 정보를 폴링한다. $\mathrm{CSCF}$ 가 메시지를 보내는 주기가 짧을 수록 $\mathrm{CSCF}$ 성능 정보는 자세히 모니터링 할 수 있으나, 트래픽이 많아지기 때문에 성능이 낮아질 수 있다. 따라 서 관리자는 이를 적절하게 조절해야한다. 관리 시스템은 다수의 $\mathrm{CSCF}$ 가 존재할 경우 주기적으로 Get 메시지를 보 내 $\mathrm{CSCF}$ 에이전트로부터 성능 정보를 추출한 후 이를 분 석하여 적절한 라우팅 테이블을 변경할 수 있다. 또한 $\mathrm{CSCF}$ 에이전트가 관리 시스템이 결정한 임계값(Tc,Tm) 를 초과하거나 특별한 이벤트가 발생할 경우Trap 메시지 를 통해 관리 시스템에게 보고하고, 관리 시스템의 Log_DB정보에 저장한다.

관리 시스템에서 $\mathrm{CSCF}$ 의 성능 정보를 가져 오기 위해 서는 다음과 같은 단계가 필요하다.
- 1단계 : 다수의 $\mathrm{CSCF}$ 의 성능 정보 저장

관리 시스템은 각각의 $\mathrm{CSCF}$ 에게 상태정보 요청 (Get-Request) 메시지를 보낸다. 그리고 CSCF 에이전트로 부터 응답 메시지(Get-Response)를 확인한 후 관리 시스템 은 $\mathrm{CSCF}$ 의 상태 관리 정보를 갱신한다. 관리 정보가 포 함하는 정보는 $\mathrm{CSCF}$ 의 $\mathrm{ID}$, 타입, $\mathrm{IP}$ 주소, 상태정보(사용 가능, 사용불가) 및 활성화 상태등이 포함된다.

\section{- 2단계 : $\mathrm{CSCF}$ 의 성능 정보 추출}

관리 시스템에서 $\mathrm{CSCF}$ 의 성능 정보를 가져올 경우 인 증 과정이 필요하다. 인증 정보로부터 인증을 확인 후 권 한이 있을 경우는 $\mathrm{CSCF}$ 에이전트로부터 성능 정보를 가 져올 수 있지만 인증에 실패할 경우 $\mathrm{CSCF}$ 는 관리 시스템 에게 Trap 메시지를 보낸다. $\mathrm{CSCF}$ 에는 다양한 성능 정보 가 있지만 Host Resource MIB에 정의되어 있는 host 항목 중 hrSWRunPerfCPU, hrSWRunPerfMem를 이용하여 각각 의 $\mathrm{CSCF}$ 의 $\mathrm{CPU}$ 와 메모리 사용 정보를 가져오고, 이를 저 장한다. $\mathrm{CSCF}$ 들의 메모리 및 $\mathrm{CPU}$ 정보를 이용하여 동적인 $\mathrm{SIP}$ 라우팅을 하기 위해서는 이를 각각 비교하고 분석해야 하는 단계가 필요하다. 따라서 관리 시스템에서는 $\mathrm{hrSWRun}$ PerfCPU, hrSWRunPerfMem 필드의 값을 가져와, 그 정보를 통하여 CSCF의 CPUUtilization, MemoryUtilization이 성능 정보에 저장된다. 이 과정에서 관리시스템에 의해 추출되 는 성능 정보는 $\mathrm{hrSWReunPerfCPU}$, 와 hrSW ReunPerMen 정보를 기반으로 작성된 $\mathrm{CPU}$ 및 메모리 사용률 그리고 전송지연시간(Delaytime), 처리율(Throughput)등이 있다.

\section{- 3단계 : $\mathrm{CSCF}$ 의 성능 정보 분석}

2 단계과정을 마치면 성능 정보에는 $\mathrm{CSCF}$ 에 관한 성능 정보를 가지고 있으며, 이러한 성능 정보를 바탕으로 각 각의 $\mathrm{CSCF}$ 에 대한 성능 분석을 수행한다. 성능 분석을 마치면 SIP 라우팅 우선순위(priority)를 결정하고, 라우팅 정보에 정보를 갱신 및 수정한다.

- 4단계 : 효율적인 라우팅을 위한 CSCF 우선순위 결정

최종적으로 생성된 테이블은 $\mathrm{CSCF}$ 에 대한 우선순위를 부여하고, 상태정보를 포함하는 OpenStatus 갖는다. 동적 라우팅을 위하여 최종적으로 생성되는 테이블에 포함되 는 정보는 다음과 같다. $\log _{-} \mathrm{ID}$ 는 Trap의 ID 정보, TrapType는 Trap의 종류 정보, TrapInfo는 Trap 메시지에 관한 상세한 정보, Timestamp는 Trap 메시지의 생성 날짜 및 시간에 대한 정보를 포함한다. 


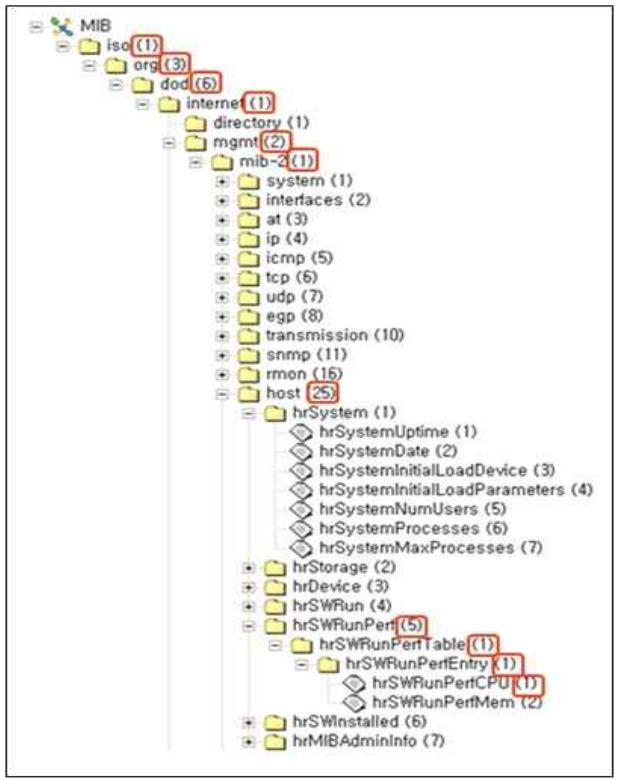

(그림 9) 동적 관리를 위한 $\mathrm{MIB}$ 구조

\section{4. 구현 및 성능 평가}

(그림 9)는 구현한 MIB 구조를 표현한 것이다. 관리시 스템에서 동적인 SIP 라우팅을 위한 관련된 성능 정보로 시스템 가동 여부, $\mathrm{CPU}$ 사용 정보, 메모리 사용 정보 등 을 고려하여 라우팅 알고리즘을 작성하였으며, $\mathrm{CSCF}$ 에는 다양한 성능 정보가 있지만 Host Resource $\mathrm{MIB}$ 에 정의되
어 있는 host 항목 중 hrSWRunPerfCPU, hrSWRunPerfMem 을 통하여 $\mathrm{CPU}$ 와 메모리 사용 정보의 값을 추출 할 수 있다.

(그림 10)은 $\mathrm{P}-\mathrm{CSCF}(\mathrm{a})$ 와 $\mathrm{S}-\mathrm{CSCF}(\mathrm{b})$ 의 $\mathrm{GUI}$ 및 $\mathrm{PoC}$, Presence Server를 표현한 것이다.

IMS 각각의 노드들은 운영체제에 의존하지 않는 Java (J2SE)로 구현하였으며, 테스트 환경에서는 $100 \mathrm{Mbps}$ 랜 이 지원되는 컴퓨터에서 처리 하였고, JAIN(Java APIs for Integrated Networks) SIP 1.2를 사용하여 P-CSCF, S-CSCF, I-CSCF를 구현하였다. (c)는 IMS 노드 관리시스템의 실행 화면을 보여 준다. 성능 정보를 얻기 위해 Detected Agent 에 $\mathrm{CSCF}$ 의 IP 주소를 추가해야 한다. SNMP OID 는 성능 정보를 얻기 위한 $\mathrm{OID}$ 정보를 나타낸다. CPU Utilization 은 $\mathrm{CSCF}$ 의 $\mathrm{CPU}$ 사용 정보를 보여주고, Memory Utilization은 메모리 사용 정보 및 사용률을 보여준다. CSCF Information은 CSCF Agent IP(CSCF Agent의 IP 주 소), sysName(서버 이름), sysDesc(서버 하드웨어와 소프트웨 어 설명 정보), sysUpDown(서버 동작 여부), hrSystemUptime (마지막으로 재 초기화 된 이후의 시간 정보), CPU_Utilization (CPU 사용 정보), Memory_Utilization(Memory 사용 정보) 등 다양한 정보를 포함하고 있다.

(그림 11)은 동적라우팅을 이용하여 $\mathrm{CSCF}$ 의 성능을 각 각 측정한 그래프이다.

본 그래프는 네트워크 관리요소 중 하나인 CPU 이용 률을 기반으로 작성하였다. (그림 11)-(a)는 CPU이용률 증 가에 따른 $\mathrm{CSCF}$ 의 응답시간을 표현한 그림이다. 그림(a) 와 같이 $\mathrm{CPU}$ 이용률이 약 $80 \%$ 이상이 되면 해당되는

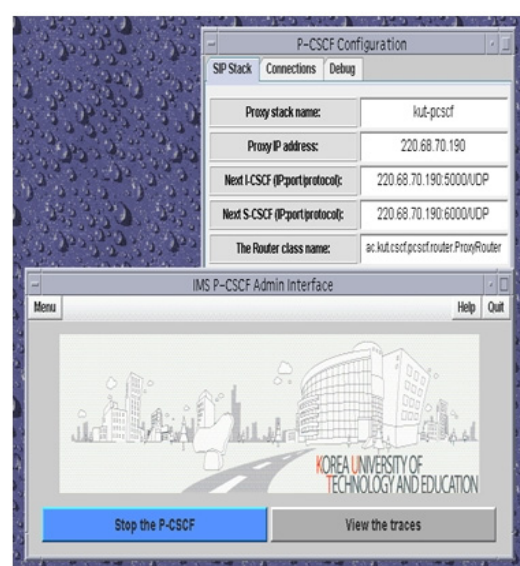

(a) P-CSCF

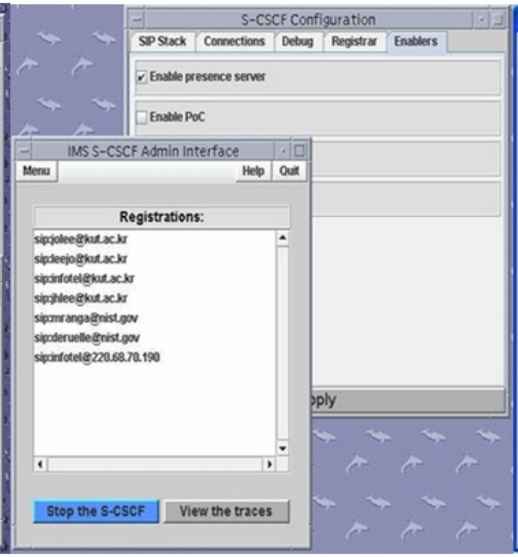

(b)PoC 서버 및 S-CSCF

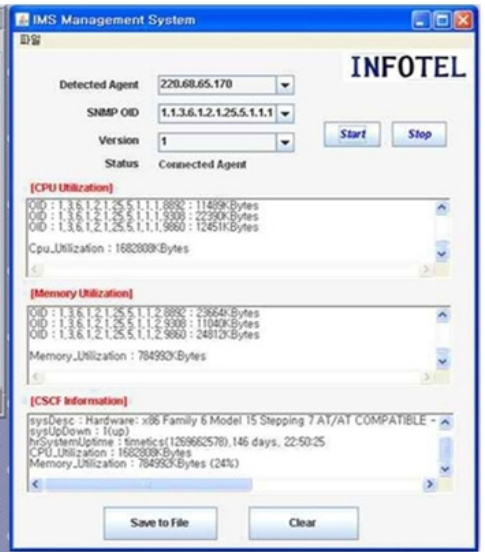

(c) CSCF 관리 시스템

(그림 10) CSCF와 PoC, Presence Server 


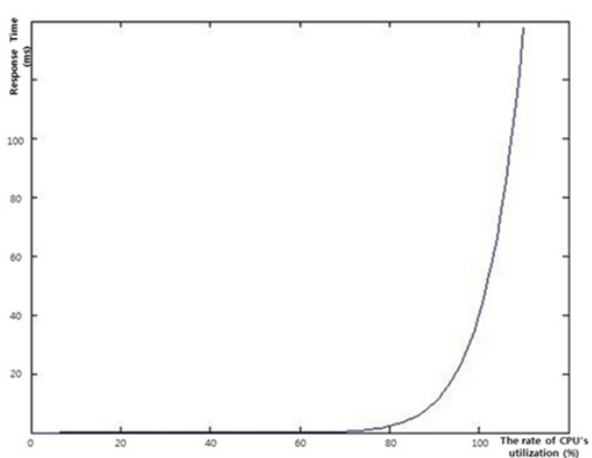

(a)CPU 이용률에 따른 CSCF 응답시간

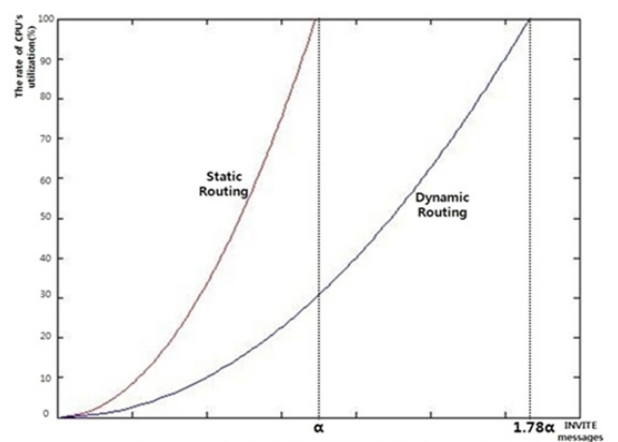

(b) INVITE 메시지 수에 따른 CSCF의 CPU 이용률 변화

(그림 11) 동적 라우팅을 이용한 CSCF 성능측정

$\mathrm{CSCF}$ 의 성능은 급격히 저하됨을 알 수 있다. (그림 11)-(b)는 $\mathrm{CSCF}$ 가 처리하는 INVITE 메시지 수에 따른 $\mathrm{CSCF}$ 의 $\mathrm{CPU}$ 이용률 변화이다. INVITE 메시지 수가 많다 는 것은 $\mathrm{CSCF}$ 가 처리해야하는 데이터양이 많다는 것이 고, 따라서 $\mathrm{CPU}$ 이용률은 자연히 증가할 것이다. 해당실 험은 3 개의 S-CSCF를 이용하여 테스트 하였으며, 정적 라우팅에 비하여 동적 라우팅 알고리즘을 이용할 경우 정 적 라우팅에 비하여 1.78 배 성능이 증가하는 것을 볼 수 있다. 따라서 다수의 S-CSCF가 존재할 경우 갑자기 트래 픽이 동적 라우팅 알고리즘을 이용하면 각각의 S-CSCF 마다 해당 트래픽을 분산시키기 때문에 정적 라우팅에 비 하여 성능이 높게 측정되는 것으로 볼 수 있다.

\section{5. 결론 및 향후 과제}

본 논문에서는 동적 라우팅 알고리즘을 이용하여 IMS 노드를 관리하였다. 또한 $\mathrm{CSCF}$ 관리를 위한 응용프로그램 으로는 PoC와 Presence Service를 구현하여 SIP INVITE 메 시지 수를 이용하여 동적 라우팅의 성능을 측정한 결과 정적 라우팅을 적용한 것에 비하여 1.78 배 성능이 향상됨 을 보았다. 향후 $\mathrm{CPU}$ 이용률뿐만 아니라 다양한 네트워크 관리 요소를 적용할 수 있는 알고리즘을 제안해야 할 것 이며, 또한 더 많은 성능정보를 추출 할 수 있도록 $\mathrm{MIB}$ 을 정의 해야할 것이다. 또한 본 연구를 이용하여 다양한 환 경에서의 시뮬레이션이 이루어져야할 것이며, 정적 라우 팅 과 동적 라우팅의 비교뿐만 아니라 다른 동적라우팅 알고리즘과의 비교분석이 이루어 져야 할 것이다.

\section{참 고 문 헌}

[1] Gonzalo Camarillo, Miguel A.Garcia Martin, "The 3G IP Multimedia Subsystem (IMS) merging the internet and the cellular worlds", WILEY, 2006.

[2] Mark Wuthnow, Matthew Stafford, "IMS : A new model for blending application", informa, 2011.

[3] Rogelio martinez perea, "Internet Multimedia Communications Using SIP", Elsevier, 2008.

[4] Jae-Oh Lee, et al, "JNMWare: Java-based Network Management Platform", APNOMS, December 2000.

[5] OMA,"Presence_SIMPLE-V1_1", January, 2011.

[6] Open Mobile Alliance (OMA), Enabler Release Definition for Push to Talk Over Cellular Candidate Version 2.0, 11 Dec 2010.

[7] RFC 3859, "A Presence Event Package for Session Initiation Protocol (SIP)", August, 2004.

[8] Jain SIP API 1.2 specification, 2006-12.

[9] Jae-Hyoung Cho, Jae-Oh Lee, "An Implementation of the SDP Using Common Service Enablers", LNCS 5787, September 2009. 


\section{저 자 소 개}

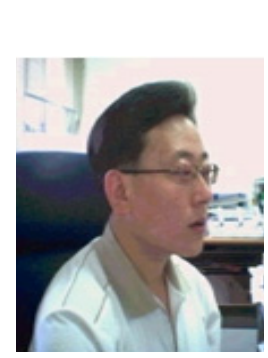

\section{이 재 오}

1987년 광운대학교 전산학 졸업(학사)

1989년 광운대학교 대학원 전산학 졸업(석사)

1993년 광운대학교 대학원 전산학 졸업(박사)

1994 1995년 코오롱 정보통신 연구소 과장

1995 2000년 한국통신 선임연구원

1999 2002년 (주)웨어플러스 연구소장

2002 현재 한국기술교육대학교 전기전자통신공학부 교수

관심분야 : IMS, 시스템 및 네트워크 관리, 객체 지향 분산 처리 기술, 네트워크 $\mathrm{QoS}$ 제어 플랫 폼, 개인화 서비스, 클라우드 컴퓨팅, IPTV QoE 설정, 통합플랫폼 개발, $\mathrm{M} 2 \mathrm{M}$, etc.

E-mail : jolee@kut.ac.kr

\section{조 재 형}

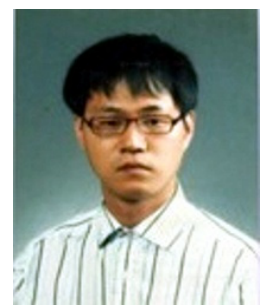

2006년 한국기술교육대학교 정보기술학부 졸업(학사)

2008년 한국기술교육대학교 대학원 전기전자공학과 졸업(석사)

2008 현재 한국기술교육대학교 대학원 전기전자공학과 수료(박사)

관심분야 : IMS, $\mathrm{QoS}$ 제어 플랫폼, 개인화 서비스, 클라우드 컴퓨팅, NMS,

E-mail : tlsd12@kut.ac.kr

$$
\text { 통합플랫폼 연구, } \mathrm{M} 2 \mathrm{M} \text {, etc. }
$$

